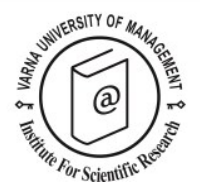

\title{
Host-guest relationship in the context of volunteer tourism
}

\author{
Raweewan Proyrungroj ${ }^{1 *}$
}

Received: 25/05/2016 Accepted: 14/09/2016

\footnotetext{
1 Tourism Industry and Hospitality Management Programme, Faculty of Humanities and Social Sciences, Suan Sunandha Rajabhat University, 1 U-Thong Nok, Dusit, Bangkok, Thailand, 10300; E-mail: raweewan.pr@ssru.ac.th, miss_raweewan_18@yahoo.com

* Corresponding author
}

\begin{abstract}
This study explores the nature of interactions and relationships between volunteer tourists and their hosts by using social exchange theory. A qualitative research methodology utilising semistructured, in-depth interviews and participant observation was adopted. The informants included fourteen volunteer tourists, on a working vacation at the Special Education Centre of Ranong Province, and nineteen staff members of the centre. Analysis of the data revealed that the interactions and relationships between the volunteer tourists and the hosts were equal, reciprocal and rewarding; neither acted only for the purpose of satisfying their own needs/expectations, but rather in ways that could benefit one another. In other words, they did not just seek to "take", but also intended to "give", which may be part of the unique nature of volunteer tourism, where volunteer tourists are driven by altruistic motivations and are viewed as different from other tourists by their hosts. Such mutual, rewarding interactions and relationships brought benefits to both groups and were sufficient for them to decide to be involved in volunteer tourism in the future.
\end{abstract}

(C) 2017 Varna University of Management. All rights reserved

Keywords: Host-guest relationship, interactions, volunteer tourism, volunteer tourists, hosts.

Citation: Proyrungroj, R. (2017) Host-guest relationship in the context of volunteer tourism. European Journal of Tourism Research 16, pp. 177-200

\section{Introduction}

Volunteer tourism is a growing form of alternative tourism. Annually, more than 1.6 million individuals pay to take part in volunteer tourism (Mostafanezhad, 2013). This form of tourism can be characterised as an integrated combination of "travel' and "volunteerism" (Raymond \& Hall, 2008); in other words, it is a form of holiday or tourism that contains a component of volunteering in the community of the destination the tourists visit.
Volunteer tourism originated in Western countries, mainly Europe and the UK; it then expanded to other regions including participants from the US, Australia, Asia, and Africa (Alexander, 2012; Lo \& Lee, 2011; Wearing \& McGehee, 2013). This type of tourism has been very popular among Westerners. Based on a study by Tourism Research and Marketing (TRAM, 2008), volunteer tourism has experienced significant growth over the past two decades: 
approximately 120,000 travellers from the US and UK volunteer abroad annually.

A combination of factors has facilitated the phenomenal growth of volunteer tourism, including the growth of mass tourism on a global scale (Callanan \& Thomas, 2005; TRAM, 2008; Tomazos \& Butler, 2009) and the power of the media (Callanan \& Thomas, 2005) to reveal other cultures to people, especially those from developed or Western countries, making them more aware of "the explicit divisions between the "haves" and "have-nots" in the society", thereby inspiring them to do something more worthwhile and meaningful through volunteer tourism (Callanan \& Thomas, 2005: 185).

Moreover, terrorism and natural disasters that have occurred in many countries also contribute to the growth of volunteer tourism. The industry report "Volunteer Travel Insights 2009" reveals that the 9/11 incident in the US in 2001 and the Boxing Day tsunami that hit many countries in Southeast Asia in 2004 serve as important factors that motivate a number of people around the world to take a holiday that involved volunteering in the destinations where natural disasters occurred (Nestora, Yeung, \& Calderon, 2009).

Kontogeorgopoulos (2016) argues that the pretrip motivations of volunteer tourists, particularly a desire for authenticity, have a role in the popularity and growth of volunteer tourism around the world. He points out that tourists in high-income countries are increasingly aware that conventional tourism experiences take place in artificial environments and create negative consequences for local communities, therefore, they seek for a form of alternative tourism that can provide authentic experiences.

In addition, Wearing \& McGehee (2013) point out other factors that have also played an important role in the growth and popularity of volunteer tourism, such as a reduction in barriers to travel, an increase in the size of the middle class in many developing countries, and

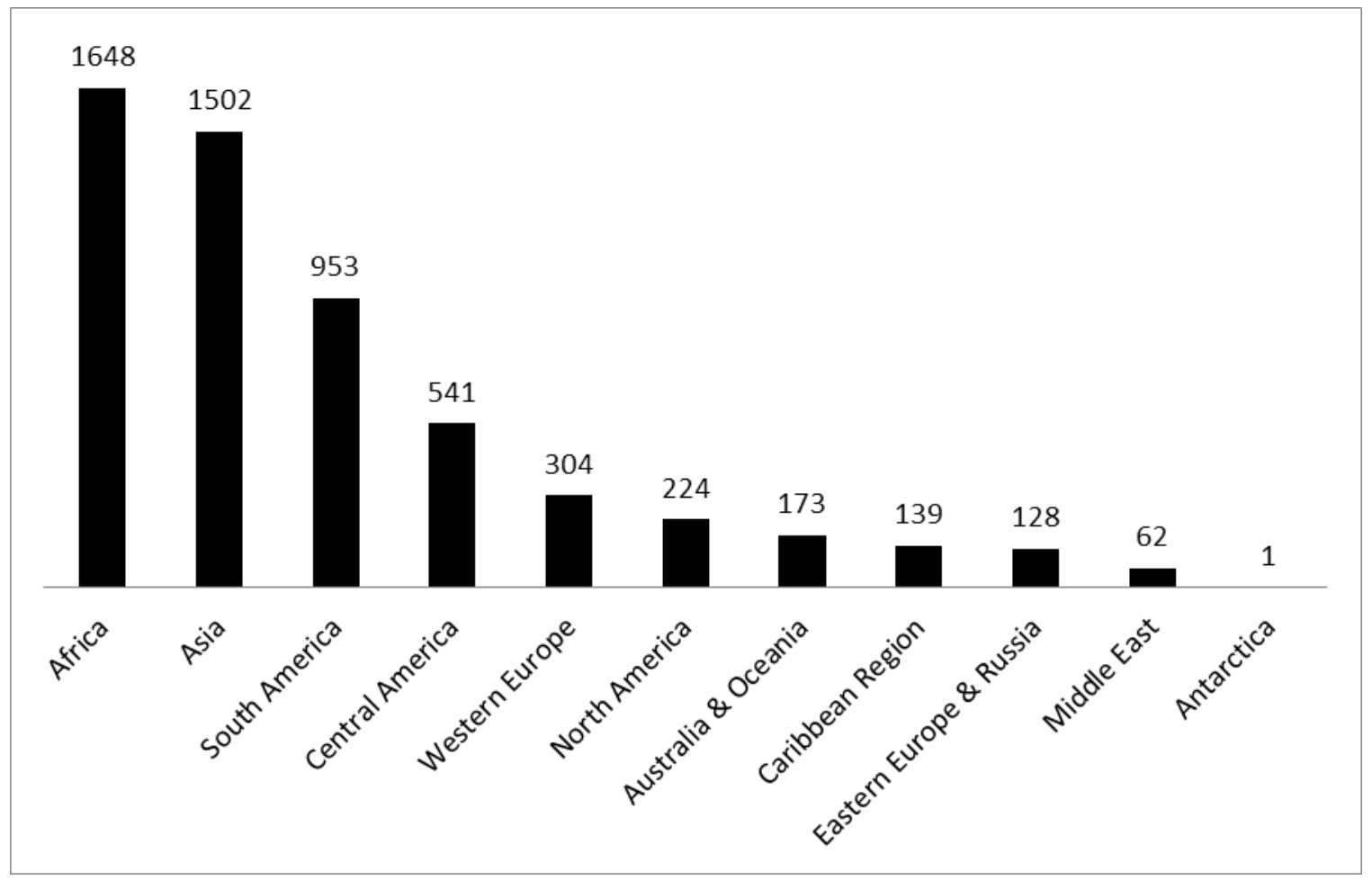

Source: GoAbroad.com (2016)

Figure 1. Number of volunteer tourism programmes offered in each region 
the desire of the middle class to gain more meaningful tourism experiences.

The growth of volunteer tourism is reflected through the growing number of volunteer tourism programmes offered (TRAM, 2008; Tomazos\& Butler, 2009). Callanan\& Thomas (2005) explored the scale of volunteer tourism in 2003 by utilising the Volunteer Abroad database and found that there were 698 volunteer tourism programmes available worldwide. Tomazos \& Butler (2009) built on this study and examined the growth of volunteer tourism using the same database, finding that by 2007 the number of volunteer tourism programmes had risen dramatically to 2,446, around 3.5 times higher than in 2003. Recent data in the same database shows that the number of volunteer tourism programmes continues to experience phenomenal growth: in May 2016 , there is a total of 5,675 programmes offered around the world (GoAbroad.com, 2016). The number of volunteer tourism programs offered in each region is shown in Figure 1.

The main destinations for Western volunteer tourists are often less privileged or developing countries (Simpson, 2004; Tomazos \& Butler, 2009; TRAM, 2008; Zahra \& Mclntosh, 2007). These countries are also referred to as "Third World" countries. According to TRAM (2008), in 2007, Latin America was listed as the single most popular region for volunteering placements, representing 36 percent of the destinations offered by volunteer tourism organisations. It was followed by Asia (28 percent) and Africa (25 percent). Together these three regions represented almost 90 per cent of all the volunteer tourism destinations. Similarly, Morgan (2010) reveals that these three regions are the most popular regions for volunteering placement (albeit in a different order: in this study, Africa ranked first, with Asia second and Latin America third). Mostafanezhad (2013) shows that Western volunteer tourists were generally interested in volunteering in a "Third World" country, rather than their home countries, because they believe that the "Third World" was where help is most needed and their contribution could have real impact.
Volunteer tourism is relatively new in Thailand. Its name appeared officially for the first time as "a promising future niche-market" in the Tourism Authority of Thailand's 2011 marketing strategy plan for the European region (Tourism Authority of Thailand, 2010). Sources, such as the Asian Development Bank (2005), Mostafanezhad (2014), Kontogeorgopoulos (2016), the United Nations Thailand (2008), and the United Nations Environment Programme (2005), point out that following the 2004 Boxing Day Tsunami, a number of international volunteers from across the world were attracted to the tsunami-affected areas in Thailand, Thailand has become one of the most popular destinations for international volunteer tourists.

Mostafanezhad (2014) points out that the growth and popularity of international volunteer tourism in Thailand also stems from the wellknown humanitarian work of celebrities such as Angelina Jolie and Ricky Martin, which have been widely highlighted in media coverage, like as a time magazine article, "Vacationing like Brangelina" (Fitzpatrick, 2007) and a CNN article, "Do celebs like Jolie inspire voluntourism?" (Vasquez, 2010). Mostafanezhad (2014) found from her study on volunteer tourism in Thailand that volunteer tourists described Angelina Jolie's humanitarian work as their inspiration to participate in volunteer tourism vacations.

Despite the rapid growth and popularity of volunteer tourism, studies of volunteer tourism are still limited. In addition, existing studies of volunteer tourism to date have been fragmented by focusing solely on the perspective of volunteer tourists, such as their motivations and/or experiences (e.g. Andereck, McGehee, Lee, \& Clemmons, 2012; Barbieri, Santos, \& Katsube, 2011; Broad, 2003; Brown, 2005; Carter, 2008; Harlow \& Pomfret, 2007; Lepp, 2009; Lo \& Lee, 2011; Sin, 2009) or the perspective of the residents in host communities (e.g. Holmes, Smith, LockstoneBinney, \& Baum, 2010; McGehee \& Andereck, 2009; Sin, 2010). In fact, both volunteer tourists and local residents are major players in volunteer tourism and play a very significant role in the success and sustainability of the development of volunteer tourism; thus, 
understanding the perspective of only one party provides only half the picture. Therefore, to gain a complete picture of the phenomenon, the perspectives of and relationships between these two groups should be obtained. Thus, this study examines the nature of interactions and relationships between volunteer tourists from Western countries and their hosts in Thailand, using a qualitative approach. Volunteer tourists and hosts are not homogeneous groups of people. They are diverse and likely to have different perceptions. With the use of qualitative research, rich, indepth, holistic insights on the nature of interactions and relationship between volunteer tourists and their hosts can be obtained.

Social exchange theory, proposed by Ap (1992), was used as a framework because it helps to understand the process, causes and consequences of the interactions and relationships between volunteer tourists and hosts throughout their interactions. SET has been widely used in tourism studies, especially in the study of attitudes of local residents on tourists and tourism development and their supports for tourism (e.g. Andereck \& Nyaupane, 2011; Gursoy, Chi, \& Dyer, 2010; Lee, Kang, Long, \& Reisinger, 2010; Nunkoo \& Gursoy, 2012; Nunkoon \& Ramkissoon, 2012; Ward \& Berno, 2011). It is argued to have made a significant theoretical contribution to the field of local residents' attitudes to tourism (Fredline \& Faulkner, 2000). However, Sharpley (2014) questions the use of SET in the study of only one party in the exchange, and its contribution to an understanding of local residents' attitudes. He argues that this theory is more appropriate for the analysis of the voluntary exchanges processed between two groups of people, rather than, focussing on only one party. Upon agreeing with this argument, this study utilises SET as a base in understanding the nature of interactions and relationships between volunteer tourists and their hosts.

\section{Literature review}

Definitions and main aspects of volunteer tourism

Volunteer tourism is a relatively new form of tourism (Wearing, 2001; Tomazos \& Butler, 2009) and a number of definitions have been proposed. Examples of well-known definitions widely cited in existing literature include Wearing (2001:1), who refers to volunteer tourism as:

"[T]hose tourists who, for various reasons, volunteer in an organised way to undertake holidays that might involve aiding or alleviating the material poverty of some groups in society, the restoration of certain environments or research into aspects of society or the environment."

VolunTourism (2011), a website dedicated to providing resources relating to volunteer tourism, defines it as:

"The conscious, seamlessly integrated combination of voluntary service to a destination, along with the best, traditional elements of travel--- arts, culture, geography, history and recreation--- in that destination."

Kontogeorgopoulos (2016: 1) describe volunteer tourism as "a form of travel that combines traditional leisure pursuits with opportunities to volunteer in an organised fashion." From these definitions of volunteer tourism, it can be seen that although volunteer tourism has been defined differently, there are two common aspects. Firstly, volunteer tourists spend part of the holiday doing volunteer activities at the destination; and secondly, volunteer tourism involves goodwill practice or altruistic motivations to benefit other people.

A review of existing literature suggests five main aspects of volunteer tourism: (i) it includes volunteering and travelling components; (ii) the volunteer tourists are motivated by goodwill or altruism; (iii) it aims to provide reciprocal benefits; (iv) it aims to promote cross-cultural exchange; and (v) it is generally undertaken by Westerners in developing countries. These five aspects are discussed in turn.

\section{(i) Volunteering and travelling}

It can be argued that volunteer tourism is a tourism activity or "holiday" because this form of tourism involves the temporary and willing movement of individuals from their usual place of work or residence to other destinations 
during their free time. However, volunteer tourism differs from other types of tourism in that it involves participating in various voluntary activities at the destination. More importantly, the tourists have to pay for the privilege of volunteering (Wearing, 2001). Volunteer tourists often pay more for their volunteer vacations than for a "normal" vacation at the same destination (Wearing, 2001). Such expenses normally cover the costs of accommodation, meals, and the maintenance costs of the project in the relevant communities. Additionally, in some cases, they also include a donation to the cause or project (TRAM, 2008).

\section{(ii) Goodwill or altruism}

The acts of the volunteer tourists are often believed to be motivated by goodwill or altruism, which potentially benefit other people (Broad, 2003; Callanan\& Thomas, 2005; Gray\& Campbell, 2007; McGehee\& Santos, 2005; Wearing, 2001). Altruism is one of the major factors motivating travellers to participate in volunteer tourism (Brown, 2005; Chen \& Chen, 2011; Lo \& Lee, 2011; Proyrungroj, 2013; Wearing, 2001). An analytical review of the literature on volunteer tourists' motivations found that altruism is illustrated in many ways, and takes a variety of forms. Phrases such as "giving back" (Brown, 2005), "making a difference" (Brown, 2005; Lo \& Lee, 2011), "saving the world" (Wearing, 2001), "doing good" (Wearing, 2001), "showing love and care" (Lo \& Lee, 2011), "helping others" (Carter, 2008; Chen \& Chen, 2011; van der Meer, 2007; Wearing, 2001), "contributing" (Sin, 2009), and "doing something meaningful" (Lo \& Lee, 2011) are used to describe altruistic motivation.

In terms of the actions volunteer tourists use to express altruistic motivation, these take a number of forms, such as providing financial and material support to the needy, giving up their time, and using their skills and knowledge for the well-being of local residents (e.g. teaching health knowledge to students in a local school, and encouraging people in difficult situations) (Lo \& Lee, 2011; Proyrungroj, 2013).

\section{(iii) Reciprocal benefits}

Volunteer tourism is arguably a mutually beneficial form of travel (Broad, 2003; Brown \& Morrison, 2003; Lepp, 2009; Ooi\& Laing, 2010; McGehee\& Santos, 2005; McIntosh \& Zahra, 2007; Raymond \& Hall, 2008; Sin, 2009; Wearing, 2001). The potential benefits that local residents in host communities can gain from volunteer tourism can be categorised into three main areas: economic-related, socialrelated, and environment-related benefits.

The economic-related benefits include increased manpower, direct financial support through volunteering placements, local employment, and supplementary revenue (Morgan, 2010). In terms of social-related benefits, volunteer tourism not only provides a free workforce and funds to local communities (Callanan\& Thomas, 2005; Mclntosh \& Zahra, 2007; Stoddart\& Rogerson, 2004; Wearing, 2001 ), but can also provide a viable means of education for locals (Sin, 2010). As for environmental benefits, volunteer tourism that takes place in rural destinations can help with environmental restoration and conservation (Broad, 2003; Wearing, 2001).

For the volunteer tourists, the notions of selfdevelopment and transformative experiences are often mentioned in existing literature (e.g. Broad, 2003; Harlow \&Pomfret, 2007; Jones, 2005; Knollenberg, McGehee, Bynum Boley, \& Clemmons, 2014; Lo\& Lee, 2011; McGehee\& Santos, 2005; Mclntosh \& Zahra, 2007; Zahra \& Mclntosh, 2007). For example, Broad (2003), Harlow \&Pomfret (2007), Jones (2005) and Lo \& Lee (2011) all argue that the volunteer tourism experience facilitates the volunteer tourists to develop their abilities and skills in multiple ways, such as improving their confidence, enhancing their ability to work with others, gaining problem-solving skills and developing their communication skills.

\section{(iv) Cross-cultural exchange}

According to existing literature, volunteer tourism enables direct interaction and exchange between volunteer tourists and host communities (Broad, 2003; Brown, 2005; Jones, 2005; Mclntosh \& Zahra, 2007; Zahra \& Mclntosh, 2007). Brown (2005: 488) notes that: 
"volunteer experiences enable travellers to experience and learn beyond the typical tourism platform, where one is surrounded by staged settings typified by beautiful beaches and fancy resorts, to see the people as they really are, their lives and their living environment."

This is because volunteer tourists live and work in the host community, which consequently allows them to directly observe and interact with local people (Broad, 2003).

\section{(v) Undertaken by Westerners in developing countries}

Volunteer tourism is often perceived as a practice of people from Western nations travelling to provide assistance to people in developing countries (Palacios, 2010; Richter \& Norman, 2010; Scheyvens, 2002; Simpson, 2005; Sin, 2009). This practice is underpinned by the notion that the notion that the world is divided into a rich, developed "North" and a poor, developing "South". People in the "North" or Western nations were born more fortunate and ought to share their privileges by assisting people in the "South" or Eastern nations who are less fortunate.

\section{Host-guest interactions and relationships}

Tourism is a social phenomenon consisting of interactions and relationships between and among individuals, various stakeholder groups and organisations, especially between tourists and local residents (McGehee \&Andereck, 2009; Sharpley, 2014). To support this, Bimonte \& Punzo (2016: 129) states that "tourism involves a meeting of two populations: a better known, stable population (residents) and a generally ex-ante less known and variable one (tourists)", each of which has their own preference and expectations with regards to the benefits and costs deriving from tourism. The interactions and relationships that occur between local residents and tourists are often referred to as "host-guest interactions and relationships" or "host-guest encounters", in which local residents serve as host, and tourists are guests. Such interactions and relationships are argued to be fundamental to tourism (Smith (1977).
Sharpley (2008) points out that interactions and relationships occurring between local residents and tourists may influence the attitudes, expectations, opinions and, ultimately, lifestyles of both parties. Bimonte \& Punzo (2011) and Sharpley (2014) similarly state that the quality and nature of the interactions and relationships between these two groups affects local residents' perceptions of tourism and tourists' willingness to pay and their experiences. A number of scholars (e.g. Bimonte, 2008; Bimonte \& Punzo, 2016; Getz \& Timur, 2005; Gursoy \& Rutherford, 2004) argue that only mutual benefits between local residents and tourists can prevent conflicts between them based on the effects of competition and the over use of resources.

Pearce (1994) states that the contexts within which such interactions and relationships occur vary, depending on a number of factors such as the stage, scale, and type of tourism development, the expectation and behaviour of tourists, and the structure and characteristics of the local community. Sharpley (2014) conceptualises the nature of host-guest interactions and relationships based on the nature of contact between these two parties and subsequent influences on host perceptions by developing a continuum of tourist-host encounters. At one end of the continuum stands the so-called "intentional encounters between tourists and hosts based on commercial exchange" where tourists and hosts engage in frequent, planned, mutually beneficial exchanges, therefore, such encounters tend to have a direct effect on tourist experiences and the hosts' perceptions. Conversely, at the other end of the continuum is the encounter between tourists and hosts who do not have direct contact with each other, therefore, the encounter between them does not have an influence on the experience of the tourists, but possibly has an influence on the hosts' perceptions. In the middle between these two ends are intentional encounters for personal exchange and unintentional/spontaneous encounters. The former refers to the context in which tourists and hosts have occasional, planned, mutually beneficial contacts, whereas the latter refers to a context in which tourists and hosts engage in infrequent, unplanned, and uncertain beneficial 
contact. However, both forms of encounters have some degree of influence on tourist experiences and hosts' perceptions.

Apart from the nature of host-guest interactions and relationships, the status of hosts (local residents) and guests (tourists) is another concept used to describe and analyse the interactions and relationships between these two parties. Van den Berghe \& Keyes (1984) argue that local residents and tourists are unequal in terms of local information and wealth. In terms of local information and knowledge, locals are in a superior status because they are more familiar with the local information and knowledge. Thus tourists are vulnerable and likely to be cheated. However, in terms of wealth, tourists usually have better status as they come from developed and wealthy nations, whereas the locals live in developing and poor countries. Moreover, Van den Berghe \& Keyes (1984) also add that the inequality between local residents and tourist also comes from the fact that tourists are the onlookers while the local residents are the performers.

In line with this, Zhang, Xu, \& Xing (2016) explain the unequal status between local residents and tourists by stating that tourists are usually in an active position through "gazing" and "photographing" the local residents, while the local residents are often in a passive position because they are those who are gazed upon and photographed by the tourists. In addition, the study of Zhang et al.(2016) on host-guest interactions in ethnic tourism argues that in a particular location such as in minority or ethnic areas, the hosts appear to have higher status and more power than tourists through their control of the space and their local knowledge. Moreover, this study also suggests that in minority areas, due to the lack of local knowledge, superiority of tourists' economic position does not make them have higher status or more power than the local residents.

\section{Social exchange theory (SET)}

The analytical review of social exchange theory (SET) presented in this section provides a foundation for understanding the interactions and relationships between volunteer tourists and their hosts. SET is rooted in sociology and anthropology (Cook \& Rice, 2003) and has been applied widely in a business context (Coulson et al., 2014).

The theoretical core of SET is an assumption that all relationships are exchanges which involve give and take (Kaynak \& Marandu, 2006). Specifically, SET is based on the premise that social interaction is based on an exchange of tangible and intangible rewards and resources between people or groups of people (Nunkoo \& Ramkissoon, 2012; Sharpley, 2014; Zafirovski, 2005), and the comparison between relative costs and benefits of such relationships (Ward \& Berno, 2011). In other words, SET is concerned with the analysis of how the structure of costs and benefits in a relationship affect the pattern of interaction (Molm, 1991). According to SET, individuals decide to engage in an exchange process once they have anticipated and compared the benefits which they may gain from such an exchange with the costs that they may incur (Bimonte \& Punzo, 2016; Nunkook \& Ramkissoon, 2012). Generally, individuals involved in an exchange process will enter into relationships in which the benefits exceed the costs (Nunkook \& Ramkissoon, 2012) and try to optimise the benefits while minimising the costs implied by such exchange (Bimonte \& Punzo, 2016; Coulson et al, 2014).

Ap (1992: 668) conceptualised social exchange theory as

"a general sociological theory concerned with understanding the exchange of resources between individuals and groups in an interaction situation. Interactions are treated as a process in which "actors" supply one another with valued resources," defining an actor as "a person, a role-occupant, or a group that acts as a single unit" and resources as "of a material, social, or psychological nature", which "become the object of exchange."

Sharpley (2008) suggests that in the context of tourism, tourists and hosts go through a process of negotiation, exchange or interaction in which both aim to benefit from the encounter. Cropanzano \& Mitchell (2005: 876) argue that "an exchange requires a bidirectional 
transaction - something has to be given and something returned". For example, while tourists may seek to benefit in a form of a desired experience and hosts in the form of economic gain, each party provides the other with resources (e.g. tourists buy souvenirs, local residents arrange cultural shows).

A number of researchers (e.g. Bachmann, 2001; Cook, Hardin, \& Levi, 2005; Nunkoo \& Ramkissoon, 2012; Oberg \& Svensson, 2010) argue that central to SET are the concepts of power and trust between the actors in an exchange process. Or in other words, social exchanges are based on a mixture of both power and trust (Bachmann, 2001). Nunkoo \& Ramkissoon (2012) explain the notion of power by using Foucault (1978)'s concept of modern power and state that power in the context of SET is not similar to the traditional perspective on power where it refers to a situation where one person or a group of persons gives orders and the other obey (Stein \& Harper, 2003), but in the context of SET, power exists and is manifested in all social relations. In line with this, Ap (1992) points out the role of power in social exchanges by stating that power is used to achieve mutual benefits between the actors involved in the exchange process and it also determines the actors' ability to take advantage of the outcomes of the exchange.

Alongside the notion of power is trust. Several scholars (e.g. Cropanzano \& Mitchell, 2005; Molm, Takahashi \& Peterson, 2000; Nunkoo \& Ramkissoon, 2012; Stein and Harper, 2003) argue that trust between actors serves as a key element in social exchanges. This is because in social exchanges, the exchange of benefits between actors is a voluntary action and is not based on any obligations (Konovsky \& Pugh, 1994). Therefore, whether social exchanges will continue is based on trust between the actors in an exchange process (Zafirovski, 2005).

Social exchange can be either reciprocal or a negotiated exchange (Coulson et al, 2014). Reciprocal exchange refers to an exchange in which each party involved in an exchange process performs beneficial acts for another without the negotiation of terms and without knowing whether or not, or even to what extent others will reciprocate (Frémeaux \& Michelson, 2011; Molm, Peterson, \& Takahashi, 2003; Molm et al., 2000). In contrast, negotiated exchange is an exchange in which both parties seek explicit agreement on the terms of

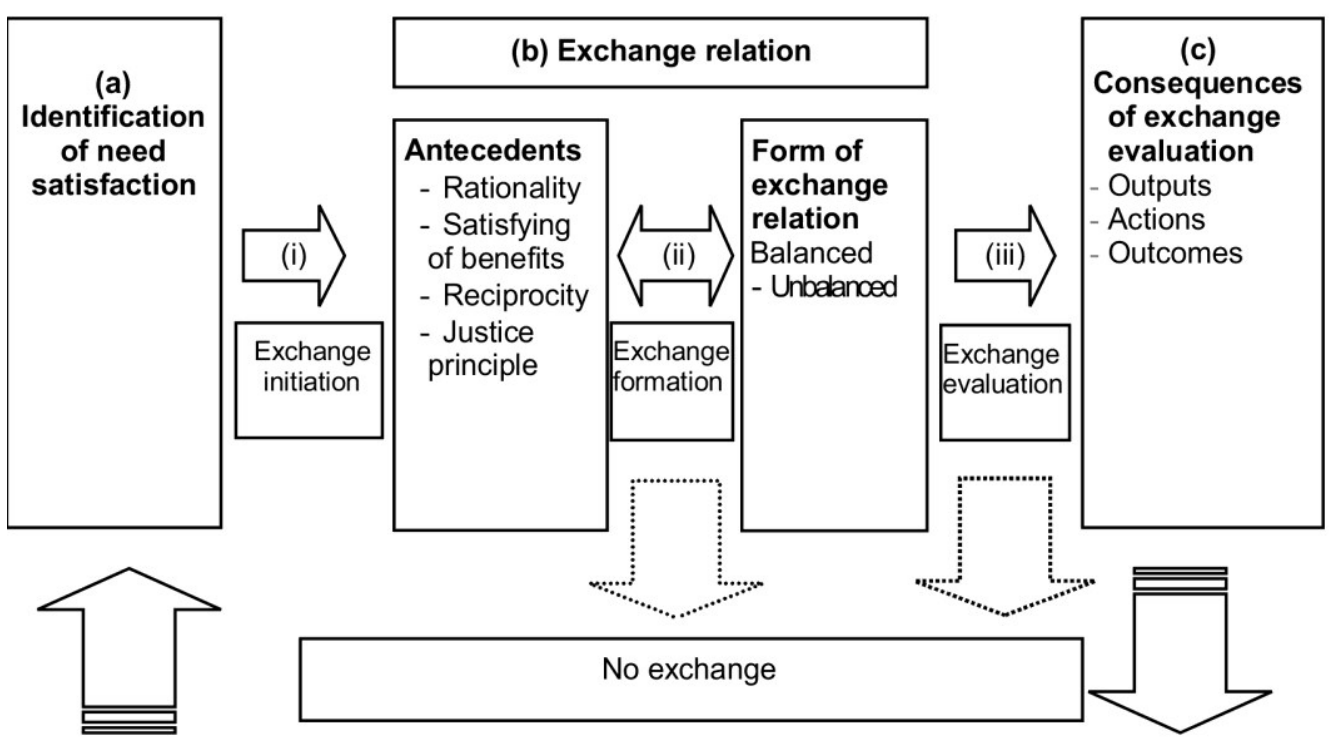

(d) Determination of the consequences (Positive exchange)

Fiqure 2. The model of the social exchanqe process 
exchange (Molm et al., 2003) and thus each party's benefits and costs are of measured value (Coulson et al, 2014).

When applied in the context of tourism, Ap (1992) explains that social exchange consists of four main components: (a) the identification of need satisfaction; (b) exchange relation; (c) consequences of exchange; and (d) determination of the consequences. Between these components are a set of processes that link them together, including: (i) initiation of exchange; (ii) exchange formation; and (iii) exchange evaluation, as in Figure 2.

Figure 2 shows that the interaction or social exchange process between tourists and hosts is initiated by the "identification of need satisfaction" which serves as the rationale or motivation for each party to engage in tourism activities. These motivations play an important role in influencing the attitudes and behaviour of tourists and hosts during the interactions (Fisher \& Price, 1991; Proyrungroj, 2013). Fisher \& Price (1991) argue that two types of motivations (a desire to learn something new and a desire to interact with new people) determine the positive results of host-guest interactions. Identification of need satisfaction is linked to the second component, the "exchange relation", by a process of initiating an exchange.

According to Ap (1992), exchange relations consist of two subcomponents: antecedents and form of exchange relation, linked by a process of exchange formation. The antecedents refer to forms of opportunities perceived by at least one of the actors before the exchange occurs. The antecedents or perceived opportunities normally occur in forms of, initially, "rationality of behaviour", when the actors believe that they can gain potential rewards or benefits from exchange; therefore, tending to act in a rational manner that leads them to obtain such benefits; "satisfying of benefits", in which actors attempt to gain a satisfactory and acceptable level of benefits from the exchange, since the ideal maximised benefits may not always be possible; "reciprocity", a situation in which each actor provide benefits that are important to one another equitably; and "justice principle", in which the exchange must be perceived by both parties as fair.

If either party perceives that the exchange will be unrewarding, unsatisfactory or unfair, withdrawal will occur and there will be no exchange. Alternatively, if both parties feel the exchange will provide fair, satisfactory and reciprocal rewards, they continue to undergo the process and the transfer of resources between them occurs.

Exchange relations can be either balanced or unbalanced, based on the relative power or dependence of the actors (Ap, 1992; Crawford \& Novak, 2014). Power refers to the ability of one actor to exert control over the outcome of another's experience, and arises from having resources that are valued by another actor. The resources might be money, knowledge, experience, or whatever is sought by another actor (Crawford \& Novak, 2014). If both parties perceive that they both gain from the exchange and have similar levels of power, the exchange relation is balanced. However, if one actor has high levels of power compared to the other, the exchange relation is unbalanced, placing the former in an advantageous position. A disadvantaged actor may develop negative attitudes to the advantaged actor.

De Kadt (1979: 50) argues that the nature of the interactions or exchanges between tourists and their hosts can take one of three paths: "where the tourist is purchasing some good or service from the host, where the tourist and host find themselves side by side, for example, on a sandy beach .... and where the two parties come face to face with the object of exchanging information or ideas." In relation to social exchange theory, the last situation described shows a balanced exchange relation, in which tourist and host interact on the basis of equality, respect and mutual reward.

Several researchers (e.g. Ap, 1992; Mathieson \& Wall, 1982; Reisinger, 2012; Sutton, 1967) argue that interactions and relationships between tourists and members of the local community or their hosts tend to be unequal and unbalanced in nature. Reisinger (2012) points out that since the interactions between tourists and hosts are brief and temporary, 
there is no opportunity to develop meaningful, equal, and balanced interactions and relationships. Moreover, tourists and hosts have different social status, play different roles, and have different motivations: tourists are at leisure, whereas hosts are at work; tourists are to be served, whereas hosts are the servers; tourists are motivated by leisure, whereas hosts are motivated by financial gain. Such differences lead each party to develop different attitudes and behaviours towards each other. Above all, different abilities of tourists and hosts in accessing information can lead their interactions and relationships to be unequal and unbalanced. Ap (1992: 667) furthers this argument by stating that "not all asymmetric resident-tourist exchanges favour the tourist. There are occasions when tourists may be taken advantage of due to their inadequate knowledge."

The study of Simpson (2004) on the volunteer tourism experience of gap year students affirms the above arguments. She argues that volunteer tourism experiences emphasise the great differences and inequality between the volunteer tourists and the hosts, which in turn reinforces the notion of "them" and "us". This is because the gap year-volunteer projects create a "geography" of the world where there are simplistic boundaries between developed/northern/Western countries and developing/southern/Eastern countries, and this perception, in turn, legitimises young unskilled people from developed countries coming to help people in developing countries. Simpson (2004) also points out that volunteer tourism experiences do not enable the young volunteer tourists to truly understand the nature and causes of poverty in the host country: they simply use the poverty as a means to distinguish the developed world from the developing world and adopt the idea of "luck" or "lotto logic" to explain the differences and inequality they encounter.

In line with Simpson (2004), Sin (2009) argues that volunteer tourism and a giving attitude in the volunteer tourists cannot help aid-recipients to share the privilege enjoyed by volunteer tourists; on the contrary, it mirrors the dichotomy between the superior status of Western volunteer tourists and the inferior status of aid-recipients in host countries, and reinforces the dominant position of Western nations.

Heuman (2005) point out that the exchanges between hosts and guests in the context of volunteer tourism (referred to in this study as "working holidays") appear to be in the form of "traditional hospitality" rather than "commercial hospitality": the latter is commonly found in mass tourism. According to Heuman (2005), traditional hospitality differs from commercial hospitality in that in the former, the main features of host-guest relationship (protection provided by hosts to tourists, non-monetary reciprocity, compliance of the tourists with locals' expectations, and a performance of deference) are all found, whereas these elements do not feature in the latter. In commercial hospitality, interactions and relationship between hosts and tourists are usually based on financial exchange, so that the relationships between tourists and hosts are less likely to develop social and personal ties. Agreeing with this, Uriely \& Reichel (2000) argue that volunteer tourism can serve as a platform where "social exchange" relations between hosts and guests - in which social and personal ties receive more emphasis- can be better developed.

Once the exchange process is completed, or at the end of the holiday, both tourists and the hosts evaluate the exchange of resources. The consequences of the exchange evaluation can take the form of a sequence: examining outputs from the exchange; determining the action to respond to another party based on the outputs; and evaluating the psychological outcomes of (feelings about) the consequences. The combination of outputs, actions, and psychological outcomes as consequences of the exchange evaluation forms the attitudes of tourists and hosts towards one another (Ajzen \& Fishbein, 1980) and determine the likeliness of future exchange.

The outputs are the perceived benefits that the actors have gained from the exchange. For example, if the evaluation of the exchange is positive, the outputs for the tourists can be gaining new experiences or having learnt about 
local culture; and for the hosts, they can be in the form of income or employment.

For actions, the tourists may recommend that their friends visit the community, and the hosts may extend friendliness, courtesy, and hospitality to tourists (Proyrungroj, 2015), or adapt themselves to some inconveniences caused by tourism, such as long queues for purchasing goods and services, sharing local facilities with tourists, overcrowding, noise, and traffic congestion (Teye, Sönmez, \& Sirakaya, 2002).

As far as outcomes are concerned, positive or negative feelings held by either group towards the other are good examples of outcomes. The study of Proyrungroj (2013) found that at the end of the holiday, volunteer tourists had mixed feeling toward their hosts as a result of their interactions: they were very impressed by the hosts' friendliness, helpfulness, and dedication to looking after the orphan children, and at the same time, they were frustrated because sometimes the hosts did not assign them work, which made them feel underutilised, useless and unneeded.

As for the hosts' feelings towards the tourists as the result of the interaction, in the field of volunteer tourism, there several relevant studies. For example, Proyrungroj (2015) reports that hosts expressed a variety of positive feelings towards the volunteer tourists, which included: being impressed (e.g. by the volunteer tourists' conduct, performance and the benefits they had provided); being grateful (for the volunteer tourists' generosity, efforts, and dedication); and being proud (of their own culture when the volunteer tourists showed an interest in it). Sin (2010) reports that hosts had positive feeling towards volunteer tourists because they were aware of the good intentions of the volunteer tourists and saw their acts as beneficial. Guiney (2012) reports that the staff of the orphanage where volunteer tourism took place had positive feelings towards the volunteer tourists, because they see the volunteer tourists as a vital source of income for the orphanages. Negative feelings of hosts towards volunteer tourists were also found in the existing literature. For example, Lo \& Lee (2011) reveal that the hosts felt inferior and frustrated when they interacted with volunteer tourists from wealthier countries

The combination of the evaluation of outputs, actions and outcome leads to decisions by both parties about their future exchange; if the exchange is positive, they are likely to engage in future exchange; but if negative, the possibility of future exchange is very low.

\section{Methodology}

This study used an interpretive paradigm and qualitative research methods because its primary aim was to gain a rich, in-depth, holistic understanding of the interactions and relationship between volunteer tourists from Western countries and their hosts in Thailand. The rationale for employing this approach is justified in terms of ontology, epistemology and methodology.

Ontologically, this research posits that the interactions and relationship between volunteer tourists and hosts are socially constructed and based on routine interrelations and interactions between volunteer tourists, hosts and the environments in a specific context. Therefore, interpretation of this phenomenon naturally varies across time and place (Jennings, 2001) and depends on the individuals who interpret it (Denzin, 1989). Further, this study holds that volunteer tourists and hosts are not homogenous groups of people: their interpretations are diverse. This ontological assumption is in accordance with the interpretive paradigm.

In terms of epistemology, the interpretive paradigm emphasises a close relationship, social interaction, and working partnership between researchers and researched, which is believed to be fundamental for meaning and knowledge production (Goodson \& Phillimore, 2004; O'Donoghue, 2007). Therefore, researchers are encouraged to immerse themselves in the social setting of interest so that an insider's view can be achieved (Jennings, 2001).In this study, the researcher adopted the case study approach, utilising a combination of qualitative research methods as a means of entering and becoming an actor in the volunteer tourism phenomenon at the study site. This approach proved very effective and enabled the researcher to work closely with the 
respondents in the production of knowledge for this study.

In keeping with the interpretive paradigm, this study was informed by a qualitative methodlogical approach, because the interactions and relationships between volunteer tourists and hosts are complex and dynamic in nature, and thus cannot be conveyed and presented in a numerical or statistical form. It is believed that the statistical nature of quantitative research cannot capture the multiple realities of interactions and relationships between volunteer tourists and hosts, and qualitative methods can lead the researcher to better understand how these two groups interpret their interactions and relationships. Therefore, this study adopted a case study approach using semi-structured interviews and participant observation.

This study employed a case study approach, using the volunteer tourism programme offered by the Special Education Centre of Ranong Province in Muang district, Ranong province, Thailand as the case. It is a government organisation established in 2000 to provide residential education and care for children with disabilities. The children include those with mental retardation, cerebral palsy, autism, mobility and physical impairments, intelligence or memory impairment, and aural impairment.

The centre began to offer the volunteer tourism programme in 2011. All the volunteer tourists applied for the program through Andaman Discoveries, a non-profit organisation based in Thailand. Over $90 \%$ of the volunteer tourists are from the UK and Spain; the rest are from other Western countries including the Netherlands, France, and Australia. Opportunities for volunteer tourism are available all year round. Generally volunteer tourists spend around one to four weeks and are required to work five days a week. Their main duty is to educate and take care of the children at the centre.

In terms of qualifications, the Special Education Centre does not require specific qualifications for recruiting volunteer tourists in terms of knowledge, skills or experiences. Instead, it prefers characteristic such as being open- minded, proactive, patient, mature, flexible and respectful of different cultures. The volunteer tourists were asked to write a motivation letter, submitted with the application form.

This study collected data from two groups of respondents: volunteer tourists on working vacations at the Special Education Centre of Ranong Province, and the staff of the centre who served as hosts. Host respondents were limited to only the staff of the centre is because, apart from the staff members of the centre, there were only a few locals who had contact with the volunteer tourists or had an opinion about them. This limitation was identified during the pilot study when the researcher tried to interview other groups of local residents, but found that they did not have rich information about the volunteer tourists to share. Generally, they said that they liked to have these people in their community, but that was all. The staff of the centre were found to be the only group of local people in regular contact with volunteer tourists.

Both groups of respondents were selected using purposive sampling. The main reason for this was that the Special Education Centre of Ranong Province is a specific, enclosed site where all the volunteer tourists and staff work, and therefore all of them had direct experience that yielded valuable insights for the research.

The criteria for selecting volunteer tourists were that subjects must be: (i) tourists from Western countries who spend part of their holiday volunteering at the Special Education Centre of Ranong Province for at least one week; (ii) aged eighteen years or older for ethical reasons; and (iii) able to communicate in English for the convenience of data collecting. As for the host respondents, the criteria for selection were that subjects must be: (i) Thai citizens; (ii) aged eighteen years or older for ethical reasons; (iii) must work at the Special Education Centre and have roles and activities that involve them with the volunteer tourists. As a result, 14 volunteer tourists and 19 staff members of the centre were selected. This number was defined by the saturation point of the data; that is, when new categories or themes stopped emerging from the data. 
Tables 1 and 2 show the profile of the respondents.

The study was conducted between January and March 2013. Data were collected using semi-structured interviews and participant observation. These two techniques were used for the benefit of triangulation. The rationale for choosing semi-structured interviews lies in their potential to enable a researcher to gather "rich" data because it allows a researcher to clarify and probe the topics being investigated (Bebbie, 1990). If the answers of the respondents are unclear or too brief, this technique enables a researcher to ask for clarification, by giving an example or simply requesting more detail (Carey, 2013). Moreover, this type of interview corresponds to the interpretive paradigm, which is the framework of this study. All 33 respondents were interviewed individually. Interviews were conducted in English with the volunteer tourists and in Thai with the hosts. Before starting the interview, the process of ensuring ethical practice was introduced. All the respondents were provided with a research information

Table 1. Profile of the volunteer tourists

\begin{tabular}{|c|c|c|c|c|c|c|}
\hline Name & Gender & Age & $\begin{array}{l}\text { Marital } \\
\text { status }\end{array}$ & Education & $\begin{array}{l}\text { Country of } \\
\text { Origin }\end{array}$ & Occupation \\
\hline V1 & Male & 18 & Single & A-levels & UK & Student \\
\hline V2 & Female & 18 & Single & A-levels & UK & Student \\
\hline V3 & Male & 22 & Single & A-levels & Netherlands & Recent university student \\
\hline V4 & Male & 19 & Single & A-levels & UK & Student \\
\hline V5 & Female & 18 & Single & A-levels & UK & Student \\
\hline V6 & Female & 21 & Single & Bachelor's Degree & Spain & Recent graduate \\
\hline V7 & Female & 19 & Single & A-levels & UK & Student \\
\hline V8 & Female & 32 & Single & Bachelor's Degree & UK & Teacher \\
\hline V9 & Male & 23 & Single & Bachelor's Degree & Spain & Recent graduate \\
\hline V10 & Female & 41 & Married & Bachelor's Degree & Spain & Physiotherapist \\
\hline V11 & Female & 22 & Single & Bachelor's Degree & Australia & Recent graduate \\
\hline V12 & Female & 27 & Single & Bachelor's Degree & Spain & Engineer \\
\hline V13 & Female & 18 & Single & A-levels & UK & Student \\
\hline V14 & Female & 18 & Single & A-levels & UK & Student \\
\hline
\end{tabular}

Table 2. Profile of the staff members of the centre

\begin{tabular}{|c|c|c|c|c|}
\hline Name & Gender & Age & $\begin{array}{l}\text { Marital } \\
\text { status }\end{array}$ & Education \\
\hline H1 & Female & 37 & Married & Master's Degree \\
\hline H2 & Female & 42 & Married & Bachelor's Degree \\
\hline H3 & Female & 23 & Single & Bachelor's Degree \\
\hline H4 & Female & 52 & Married & Bachelor's Degree \\
\hline H5 & Female & 38 & Single & Bachelor's Degree \\
\hline H6 & Female & 32 & Divorced & Bachelor's Degree \\
\hline H7 & Male & 50 & Married & Bachelor's Degree \\
\hline H8 & Female & 50 & Single & Bachelor's Degree \\
\hline H9 & Female & 25 & Single & Bachelor's Degree \\
\hline H10 & Female & 26 & Single & Bachelor's Degree \\
\hline H11 & Female & 28 & Single & Bachelor's Degree \\
\hline H12 & Male & 31 & Single & Bachelor's Degree \\
\hline H13 & Female & 32 & Single & Bachelor's Degree \\
\hline H14 & Female & 31 & Married & Bachelor's Degree \\
\hline H15 & Male & 25 & Single & Bachelor's Degree \\
\hline H16 & Male & 23 & Single & Bachelor's Degree \\
\hline H17 & Female & 24 & Single & Bachelor's Degree \\
\hline H18 & Female & 24 & Single & Bachelor's Degree \\
\hline H19 & Female & 26 & Single & Bachelor's Degree \\
\hline
\end{tabular}


sheet that explained the details of the research and their rights. Moreover, they were asked to fill in and sign a consent form giving their permission to video-record the interviews and the use of their words with pseudonyms in publications.

As for the participant observation, this study used the technique "participant as observer" as categorised by Junker (1960), in which the respondents were aware of the researcher's identity and role. In this study, the researcher observed the behaviour of, and activities performed by, the respondents. Moreover, she had informal conversation with them. The rationale for utilising this technique lie in its strengths in allowing a researcher to gain data on what actually and normally happens in the social setting being studied (Carey, 2013). This technique also enables the researcher to be aware of the hidden aspects of events being researched (Denscombe, 2007). In addition, the researcher also believed that participant observation could enable her to become immersed in the social setting, thereby providing an opportunity to observe how the respondents construct and interpret meanings and knowledge of the issues being studied (Jennings, 2001). The activities and behaviour of the respondents, as well as informal conversations with them, were observed and recorded in the fieldnotes, which were organised chronologically.

Data analysis was conducted during and after data collection. Although software qualitative data packages like Nvivo are available, the researcher chose to analyse the data manually because this allowed her to immerse herself in the data. Before starting data analysis, the interviews were transcribed by the researcher. Although this was time-consuming, it was worthwhile because the researcher became very familiar with the data. The data gathered from semi-structured interviews and participant observation were cross-checked. This study not only sought convergence, but also differences or contradictions that occurred within the data. The data analysis process followed six phases of thematic analysis, as introduced by Braun \& Clarke (2006): (i) becoming familiar with the data; (ii) generating initial codes; (iii) searching for themes; (iv) reviewing themes; (v) defining and naming themes; and (vi) producing the report. Key themes were established according to the interpretation of meaning attached to the data in relation to the research questions.

The reason for using thematic analysis lies in its accessibility and flexibility. As suggested by Braun \& Clarke (2006), thematic analysis is an accessible and flexible method because it is not attached to any particular theoretical or epistemological approach; thus it can be applied across different theoretical frameworks.

\section{Discussion of findings}

By using the model of social exchange theory proposed by Ap (1992) to examine interactions and relationships between volunteer tourists and hosts, the data analysis reveals that both volunteer tourists and the hosts initially decided to get involved in the volunteer tourism program at the Special Education Centre because they expected to benefit from volunteer tourism.

For the volunteer tourists, three major motivations/expectations were identified: a desire to help children less fortunate than them; a desire to gain experiences in teaching and taking care of children with disabilities; and a desire to learn about Thai culture, as described below:

"These kids are very poor. I always want to help them. I feel lucky and at the same time I also feel that I am selfish, being born as a privileged person...it would be really selfish to not go and to give some love and some help to the children who are less fortunate...I really want to help them, at least to make them happy". (V2)

"I decided to work here because I want to work with children with disabilities, I want to help them get better. So for me volunteering here helped me to see how good I am at teaching and taking care of these children. I also want to see how my contribution affects them, so see how I can improve." (V7)

"It is mostly just to help ease myself into Thai culture. I always want to be immersed into the culture of the community I visit. I want to learn and experience how people live. I believe that 
working here helps me absorb myself in everything Thai." (V9)

As for the hosts, they mentioned that there were not enough staff at the centre to support the large number of children, and therefore they needed assistance from the volunteer tourists to relieve them from routine work such as taking children to toilets, taking care of children during lunchtime, and playing with children. With volunteer tourists relieving them from such responsibilities, they had more time for other tasks. Many hosts also mentioned that they wanted to learn English from the volunteer tourists. Moreover, the hosts also wanted to learn from people who have knowledge such as how to provide physical or musical therapy. For example, $\mathrm{H} 4$ said,

"We don't have a physiotherapist here because we don't have budget to hire one. So I think if we can have volunteers who are physiotherapists, we can learn a lot from them...We used to have one volunteer from Spain who is a physiotherapist and she taught us a lot. Now some of us can provide physiotherapy to the children."

The identification of needs satisfaction of the volunteer tourists and the hosts supports the argument made by Ap (1992: 671) that, "Unless a need exists, there is no rationale, motivation, or basis upon which the actor can develop a willingness to initiate exchange with another party."

When the volunteer tourists arrived at the centre and engaged in volunteer tourism programme, they interacted with their hosts. It is evident from the data that both volunteer tourists and hosts interacted in a rational manner, or in a manner they believed could lead them to fulfil their needs/expectations. For example, those tourists with a desire to gain experience in teaching and taking care of children with disabilities tended to work hard, preparing for lessons, using their skills and knowledge and trying different techniques in teaching and providing care to the children to ensure that their needs were satisfied.

For the hosts, it was found that they also acted in a rational manner to fulfil their needs/expectations, by assigning specific tasks to the volunteer tourists that they believed would benefit them and the children. For example, if the volunteer tourists had specific skills or knowledge (e.g. of physiotherapy or a particular musical instrument), these tourists would be asked to use their knowledge and skills to provide care or teach the children under the observation of the staff, so that the hosts could learn these skills as well.

It is evident that the behaviour of each group and the interactions between them brought about benefits that were perceived to be satisfactory, acceptable, and reciprocal to both groups. Neither acted only for the purpose of satisfying their own needs/expectations, but to benefit one another. In other words, they did not just seek to "take", but also intended to "give." This may be part of the unique nature of volunteer tourism, which aims to provide mutual benefit for both tourists and hosts.

The reciprocal exchanges or interactions between the volunteer tourists and the hosts found in this study support the argument that volunteer tourism provides reciprocal benefits for both volunteer tourists and host communities made by several researchers (e.g. Broad, 2003; Brown \& Morrison, 2003; Lepp, 2009; McGehee \& Santos, 2005; Mclntosh \& Zahra, 2007; Ooi \& Laing, 2010; Raymond \& Hall, 2008; Sin, 2009; Wearing, 2001). Based on the satisfactory, reciprocal interactions between volunteer tourists and hosts as discussed above, it can be argued that their interaction was a balanced exchange. This is because each party had resources valued by the other, and these resources were shared in an equal and fair manner: for example, the volunteer tourists had knowledge of English and skills in taking care of children with special needs, which they shared with the hosts; and the hosts had an environment where the volunteer tourists gained the benefits they sought.

Although both volunteer tourists and hosts perceived inequality between them in terms of their socio-economic background, this perception did not cause unbalanced interactions between them. On the contrary, both felt that they could benefit from this 
inequality. Volunteer tourists claimed that being first-hand witnesses of the differences between their own lives and the lives of the children at the centre made them aware of things that they had never realised before, transforming some of their values and perceptions. They had not only taught the children, but learnt a lot from them. The most frequently cited things they had learnt were appreciation of things they already had, and the minimal importance of material needs. As V13 said:

"The lives of the kids here made me realise that you can live simply and be so happy over this simple thing... It is so materialistic at home and the kids there have so much and yet they have no appreciation of it...I noticed that yesterday when the kids were getting their presents, that was amazing. They looked so happy even they didn't know how they could use those things."

As for the hosts, they benefitted from such inequality by learning from the skills and knowledge of the volunteer tourists. This point was clearly stated by $\mathrm{H} 3$ :

"They [the volunteer tourists] came from developed countries, which is good for us here and the kids because they know a lot of things better than us. They know how to teach and provide care for these kids better than us. I think in their countries, there are modern and more efficient ways and techniques to help these kids in terms of the development, which they can share with us."

The data also suggested that the volunteer tourists felt that they were not mere visitors, but rather guests of the centre. This made them feel warm, as if they were at their own home. The point is mention by every volunteer tourist, who similarly stated that all of the staff were very friendly and treated them as if they were family.

V14 said that she believed that the staff of the centre viewed her and other volunteer tourists as different to other tourists. She compared her previous leisure tourism experience in Thailand when she visited famous tourist attractions with her volunteer tourism experience at the centre, saying that the way Thai people treated her when she was a leisure tourist was totally different to the way the staff treated her. When she was a leisure tourist, Thai people saw her as source of money and treated her as "a customer", whereas at the centre, she was treated as "a guest".

As for the hosts, they thought that volunteer tourists were different from other tourists because they came to help. With this realisation, they felt gratitude to the volunteer tourists and wanted to return the generosity and good intentions of the volunteer tourists. Many hosts said that they had, for example, taken volunteer tourists to markets and nearby tourist attractions during the weekends and teaching Thai language to them.

Signs of caring for the safety and security of the volunteer tourists were also detected from the hosts. Many hosts said that they were worried that the volunteer tourists might have problems with the unfamiliar food and climate of Thailand; therefore, they made sure that the accommodation the volunteer tourists were equipped with enough fans and clean food was prepared for the volunteer tourists.

No sign of conflict between the volunteer tourists and the hosts were found. The data from participant observation showed that the hosts set very clear rules about working, and explained these rules to the volunteer tourists during the orientation. The hosts were also eager to explain about local culture (e.g. how to dress when visiting the temple, how to greet each other, how to speak Thai language etc.) to the volunteer tourists. Most of the volunteer tourists showed that they were ready to follow the rules and respect local culture. However, it was found that there were a couple of female volunteer tourists who dressed in a way that showed too much skin, which is considered inappropriate in Thai culture. Although some hosts mentioned their concern, they thought that this was a minor issue. They understood that the volunteer tourists did not have bad intentions, but simply dress according to their own culture, which has more liberal norms about how much skin is shown; moreover, Thailand is a hot country, so volunteer tourists who came from colder countries wore very light clothes that might show a lot of skin. 
In summary, the consequences of the interactions between tourists and hosts in this study were found to be positive. Based on social exchange theory, this can be explained using the form of a sequence: examining outputs from the interactions; determining the action to respond to another party based on the outputs; and evaluating the psychological outcomes (feelings about) of the consequences.

The outputs were in the forms of benefits that each party had gained: the volunteer tourists gained a desired experience, which included the opportunity to exercise their altruistic motivation by helping less fortunate children, having experiences in taking care of children with special needs; learning about Thai culture; and learning from the lives of the children (e.g. appreciation of things they already had, and the minimal importance of material needs). For the hosts, the benefits that they had gained include having learnt knowledge and skills from the volunteer tourists in terms of taking care of the children with special needs, having an opportunity to learn/improve English skills, and relief from routine duties and responsibilities.

In terms of action, the data showed that many volunteer tourists provided on-going support to the centre, and many of them recommended that their friends participate in volunteer tourism at the centre; for the hosts, examples include extending hospitality to the volunteer tourists and giving them souvenirs and certificates.

As for the psychological outcomes, it was found that both parties were greatly satisfied. The data showed that these positive feelings were primarily based on the characteristics and behaviour of both parties. For example, the volunteer tourists were impressed by the behaviour of the children and the dedication and performance of the staff in taking care of the children, as reflected in V9's statement that, "Seeing the development of these kids, they are so far in advance. They [the staff members] are doing a great job with engaging the kids... They have been so dedicated." The hosts were impressed by and grateful for the generosity and dedication of the volunteer tourists. Moreover, it is also evident that both parties shared an interest in the well-being and development of the children, which caused them to have positive feelings and attitudes towards each other.

Furthermore, although it was found that the volunteer tourists had some negative feelings, these were not related to the hosts, but rather a more general sense that their contribution would not be as beneficial as they expected, as stated by $\mathrm{V} 10$ :

"I just felt like the kids don't really need us here...I think there will be other centres, maybe bigger ones, where volunteers will be more needed...It feels like we are coming in, intruding a little bit on their space kind of thing."

Another factor that caused negative feelings in volunteer tourists was breaking the bond they had established with the children and the staff at the centre; this feeling inevitably occurs when two parties have spent time together. The sadness of the volunteer tourists was not as a result of any inappropriate behaviour on the part of the hosts, but caused by their own sensitivity.

These outputs, action, and outcomes determined the future involvement in volunteer tourism of both groups. Many volunteer tourists mentioned that they intended to volunteer at the centre again, and all of the hosts were willing to welcome volunteer tourists to their centre again. To conclude, the interactions in this study were reciprocal and rewarding, which benefitted both groups and was sufficient for them to decide to be involved in volunteer tourism in the future.

\section{Conclusion and implication}

The findings of this study contribute to the literature on volunteer tourism, especially in terms of the nature of interactions and relationship of the volunteer tourists and the hosts. The finding of this study agree with Fisher \& Price (1991), who point out that a desire to learn and a desire to interact with new people are the two major motivations that lead to positive results of the tourist-host encounters. In this study, these two motivations were found to be the primary motivations of both volunteer tourists and hosts to engage in volunteer tourism. It could be argued that these 
two motivations represent major characteristics of actors in volunteer tourism, because in volunteer tourism, cross-cultural exchanges and engaging relationships could be easily facilitated. A desire to learn and a desire to interact with new people were found to direct volunteer tourists and hosts to behave in a way that enabled them to gain benefits from one another, which consequently led them to have positive feelings about the experience as a whole.

The main conclusion of this study is that the exchanges or interactions between volunteer tourists and hosts tend to be equal and balanced, and both parties can enjoy mutual benefits. This finding challenges the idea that exchanges or interactions between tourists and hosts tend to be unequal and unbalanced, in which one party benefits more than the other, as argued by Ap (1992), Mathieson \& Wall (1982), Reisinger (2012) and Sutton (1967).

Perhaps an altruistic motivation or a desire to help the children on the part of the volunteer tourists, and the perception of the hosts that volunteer tourists were different from traditional tourists could best explain this situation. For the volunteer tourists, although they took care of and taught the children with the purpose of fulfilling their own desire, these behaviours evidently benefited the children and the hosts. For the hosts, they not only sought to benefit from the volunteer tourist, but also regarded them as "a member of their family" or "friends", and were willing to share knowledge of taking care of the children and their native culture with them.

Moreover, this study argues that both volunteer tourists and the hosts were very satisfied with what they gained from the other party. Neither felt that they were taken advantage of by the other party, nor believed that they were in an advantageous position. No signs of being inferior or superior were detected from either side. A possible explanation of this situation may lie in the fact that the Special Education Centre of Ranong Province does not depend on tourism's economic benefits, but on government funding. Therefore, the staff thought that the operation of the centre could still continue even without volunteer tourists. In fact, they thought that the volunteer tourists were temporary guests who come to visit and give them a hand. For the volunteer tourists, they stated that they were warmly welcomed by the staff, which made them feel as if they were guests, not tourists. Although they had to live in an unfamiliar environment and take orders from the staff to do tasks, they did not felt that this made them inferior. They also realised that the operation of the centre did not rely on their fees or on their labour was also found the volunteer tourists did not think that their wealth and knowledge from the developed world put them in a better position than the staff. Instead, they thought that participating in volunteer tourism at the centre would allow them to exchange knowledge of taking care of disabled children with the staff: something they could share with the staff and learn about together. This situation can explain why the actors in this exchange process have similar levels of power, as argued by Ap (1991) and Crawford \& Novak (2014).

In addition, the findings of this study do not support the argument that volunteer tourism may reinforce inequality between developed and developing nations, and/or deepen dichotomies of "them" and "us", instead of promoting true cross-cultural understanding between volunteer tourists and local residents, as argued by some researchers ( Lo \& Lee, 2011; Simpson, 2004; Sin, 2009). This study found that the perception of the Western volunteer tourists of the economic inequality between them and local people played an important role in influencing them to participate in volunteer tourism. The volunteer tourists felt that they were more economically fortunate and had had better opportunities than the children at the centre, creating feelings of guilt and a desire to share these benefits with others who are less fortunate. They subsequently felt that it was their responsibility or moral duty, to share their privileges. During their visit, their experiences made them more aware of their potential to help and inspired them to continue volunteering and contributing to society.

Alongside a desire to lessen inequality by sharing their privileges (e.g. taking care of the children at the centre), the volunteer tourists also sought to learn from the children, which 
they believed to be significant and applicable to their lives. Examples of such values include: appreciating what one already has; and regarding material needs as less important. The findings suggest that the staff of the centre were already aware of the inequalities between them and the volunteer tourists, but interaction with volunteer tourists did not reinforce this inequality or make the perception of it larger. On the contrary, they felt that volunteer tourism potentially lessened this gap because it served as an effective means of transferring knowledge and also promoted cross-cultural understanding. Whilst cultural differences did cause some concern among some members of the community (i.e. inappropriate dressing of volunteer tourists), such differences were not new or important.

Moreover, this study is also in agreement with Proyrungroj's (2014) study, which found that Thai residents who hosted Western volunteer tourists seem to accept the superiority of the tourists in terms of their wealth and knowledge without feeling inferior or frustrated. They believe that they could benefit from such superiority. Furthermore, the study also agrees with Kislenko (2004) and Proyrungroj (2015) that the main reason Thai hosts were not frustrated with Western tourists is that Thailand has never been colonised by Western nations; therefore, Thai locals are free from antiWestern feeling.

This study supports previous studies (Heuman, 2005; Uriely \& Reichel, 2000) that found that the interactions and relationship between volunteer tourists and hosts appear to be in a form of "traditional hospitality". Evidence of the main features of the traditional hospitality and protection provided by hosts to tourists (nonmonetary reciprocities, compliance with the expectations of hosts, and a performance of deference) were found in this study. This study agrees with Uriel \& Reichel (2000) that the nature of volunteer tourism can facilitate engaging interactions and meaningful friendships between volunteer tourists and their hosts, and in such an environment social and personal ties between both parties can be easily developed. Although there was financial exchange between volunteer tourists and hosts (the volunteer tourists paid for accommodation, food, and an opportunity to work at the centre), this was not the main feature of interactions and relationships between these two parties, as might be in the case in mass tourism.

As for practical implications, the findings of this study provide an insight for volunteer tourism organisations about the nature of interactions and relationship between volunteer tourists and their hosts. Specifically, this study provides an understanding of what each party needs or expects to gain from volunteer tourism; how each party acts or interacts with the other to ensure that their needs/expectations can be fulfilled; how each party should act and/or what should they provide for the other party in order to make their interactions and relationships balanced, equal and reciprocal. This study can serve as a case study for volunteer tourism organisations, hosts, and related stakeholders by showing how interactions between volunteer tourists and their hosts can lead each party to enjoy mutual benefits from participation in volunteer tourism.

\section{Limitations and direction for future research}

This research is underpinned by an interpretive paradigm utilising qualitative research methods, and the study is based on only one case study and a small number of respondents. Moreover, this study is primarily based on the researcher's understanding, and her interpretations of the respondents and the researcher's encounters with respondents. For these reasons, the findings of this study are unique to the volunteer tourism at the Special Education Centre of Ranong province and cannot necessarily be generalised to other cases. However, this study does not aim to generalise its findings, because such an approach is not applicable to qualitative research. Instead, it aims to gain rich, in-depth, holistic understanding of the host-guest relationship in the context of volunteer tourism; therefore, it prefers to use "transferability" as a criterion to ensure its rigour by providing thick description of the study's context and setting, in order to ensure that its findings can be transferable to other situations, if those situations are similar to the context of this study. 
In terms of future research, this study focused only on the interactions and relationships between volunteer tourists and their hosts, and the benefits each party can gain from volunteer tourism. However, it does not look at how the children did or did not benefit. They are the direct aid-recipients of volunteer tourism, and therefore, more research on the impact of volunteer tourism on children is needed.

Concerns about the impact of volunteer tourism programme on the children have been raised. At the time of conducting the research, there has been limited study on the impacts of volunteer tourism on children with disabilities. This topic can be investigated from the perspectives of people directly involved with these children, which include staff of the institutions responsible for these children, and their parents. These people are close to the children and are in a position to observe the impacts of the volunteer tourists on the children. The volunteer tourists can serve as another potential key informant because they act as care-takers and spend time with the children. Finally, people who work in the area of child psychology and/or with children with disabilities are another group of people who could provide an insight into this topic area.

\section{References}

Ajzen, I., M. Fishbein (1980). Understanding Attitudes and Predicting Social Behaviour. Englewood Cliffs, NJ: Prentice-Hall.

Alexander, Z. (2012). International volunteer tourism in South Africa: an investigation into the impact on the tourist. Journal of Hospitality Marketing and Management, 21(7), 779-799.

Andereck, K., N.G. McGehee, S. Lee, \& D. Clemmons (2012). Experience expectations of prospective volunteer tourists. Journal of Travel Research, 51(2), 130-141.

Andereck, K. L., \& G.P. Nyaupane (2011). Exploring the nature of tourism and quality of life perceptions among residents. Journal of Travel Research, 50 (3), 248-260.

Ap, J. (1992). Residents' Perceptions on Tourism Impacts. Annals of Tourism Research, 19(4), 665-690.

Asian Development Bank (2005). An Initial Assessment of the Impact of the Earthquake and the Tsunami of December 26, 2004 on
South and Southeast Asia. URL: http:// internationalbudget.org/wp-content/uploads IAn-Initial-Assessment-of-the-Impact-of-theEarthquake-and-Tsunami-of-December-262004-on-South-and-Southeast-Asia.pdf (Accessed on 01.09.2016).

Barbieri, C., C.A. Santos, \& Y. Katsube (2011). Volunteer tourism: On-the-ground observations from Rwanda. Tourism Management, 33(3), 509-516.

Bebbie, E. (1990). Survey research methods. Belmont, CA: Wadsworth.

Bimonte, S. (2008). The "tragedy of tourism resources" as the outcome of a strategic game: A new analytical framework. Ecological Economics, 67(3), 457-464.

Bimonte, S., \& L.F. Punzo (2011). Tourism, residents' attitudes and perceived carrying capacity with an experimental study in five Tuscan destinations. International Journal of Sustainable Development, 14(3/4), 242-261.

Bimonte, S., \& L.F. Punzo (2016). Tourist development and host-guest interaction: an economic exchange theory. Annals of Tourism Research, 58, 128-139.

Braun, V., \& V. Clarke (2006). Using thematic analysis in psychology. Qualitative Research in Psychology, 3(2), 77-101.

Broad, S. (2003). Living the Thai life - a case study of volunteer tourism at the Gibbon Rehabilitation Project, Thailand. Tourism Recreation Research, 28(3), 63-72.

Brown, S. (2005). Travelling with a purpose: understanding the motives and benefits of volunteer vacationers. Current Issues in Tourism, 8(6), 479-496.

Brown, S., \& A.M. Morrison (2003). Expanding volunteer vacation participation: an exploratory study on the mini-mission concept. Tourism Recreation Research, 28(3), 73-82.

Callanan, M., \& S. Thomas (2005). Volunteer tourism- deconstructing volunteer activities within a dynamic environment. In Novelli, M. (Ed.) Niche tourism contemporary issues, trends and cases. Oxford: Elsevier /Butterworth-Heinemann, pp. 183-200.

Carey, M. (2013). The Social Work Dissertation: Using Small-scale Qualitative Methodology. $2^{\text {nd }}$ ed. Maidenhead: McGrawHill/Open University Press.

Carter, K.A. (2008). Volunteer tourism: an exploration of the perceptions and 
experiences of volunteer tourists and the role of authenticity in those experiences (Unpublished Master's degree dissertation). Lincoln University, New Zealand.

Chen, L., \& J.S. Chen (2011). The motivations and expectations of international volunteer tourists: a case study of "Chinese Village Traditions". Tourism Management, 32(2), 435-442.

Cook, K. S., R. Hardin, \& M. Levi (2005). Cooperation without trust? New York, NY: Russell Sage Foundation.

Cook, K., \& E. Rice (2003). Social exchange theory. In Delameter, J. (Ed.) The Handbook of social psychology. New York, NY: Springer, pp. 53-76.

Coulson, A.B., A.C. MacLaren, S. McKenzie \& K.D. O'Gorman (2014). Hospitality codes and social exchange theory: The Pashtunwali and tourism in Afghanistan. Tourism Management, 45, 134-141.

Cropanzano, R. \& M.S. Mitchell (2005). Social exchange theory: An interdisciplinary review. Journal of Management , 31(6), 847900.

Crawford, L.A., \& K.B. Novak (2014). Individual and society: Sociological social psychology. New York, NY: Routledge.

De Kadt, E. (1979). Tourism: Passport to development? New York, NY: Oxford University Press.

Denscombe, M. (2007). The good research guide: For small-scale social research projects. $3^{\text {rd }}$ ed. Maidenhead: Open University Press.

Denzin, N. K. (1989). The research act: $A$ theoretical introduction to sociological methods. London: Prentice Hall International.

Fisher, R.J., \& L.L. Price (1991). International pleasure travel motivations and postvacation cultural attitude change. Journal of Leisure Research, 23(3), 193-208.

Fitzpatrick, L. (2007). Vacationing like Brangelina. URL http://content.time.com/ time/magazine/article/0,9171,1647457,00.ht $\mathrm{ml}$ (Accessed on 01.06.2016)

Fredline, E., \& B. Faulkner (2000). Host community reactions: A cluster analysis. Annals of Tourism Research, 27(3), 763784.

Frémeaux, S., \& G. Michelson (2011). 'No Strings Attached': Welcoming the existential gift in business. Journal of Business Ethics, 99(1), 63-75.

Foucault, M. (1978). The history of sexuality: Volume 1: An introduction. New York, NY: Vintage Books.

Getz, D., \& S. Timur (2005). Stakeholder involvement in sustainable tourism: Balancing the voice. In Theobald, W.F. (Ed.) Global Tourism. New York, NY: ButterworthHeinemann/Elsevier, pp. 230-247.

GoAbroad.com (2016). Volunteer Abroad. URL: http://www.goabroad.com/volunteer-abroad (Accessed on 01.06.2016)

Goodson, L., \& J. Phillimore (2004). The inquiry paradigm in qualitative tourism research. In Phillimore, J. L.Goodman (Eds.) Qualitative research in tourism: Ontologies, epistemologies and methodologies. London: Routledge, pp. 30-45.

Gray, N.J., \& L.M. Campbell (2007). A decommodified experience? Exploring aesthetic, economic and ethical values for volunteer ecotourism in Costa Rica. Journal of Sustainable Tourism, 15(5), 463-482.

Guiney, T. (2012). Orphanage tourism' in Cambodia: When residential care centres become tourist attractions, Pacific News, 38 July/August, 9-14.

Gursoy, D., C.G. Chi, \& P. Dyer (2010). Local's attitudes toward mass and alternative tourism: The case of Sunshine Coast, Australia. Journal of Travel Research, 49(3), 381-394.

Gursoy, D., \& D. Rutherford (2004). Host attitudes toward tourism. An improved structural model. Annals of Tourism Research, 31(3), 495-516.

Harlow, S., \& G. Pomfret (2007). Evolving environmental tourism experiences in Zambia. Journal of Ecotourism, 6(3), 184209.

Heuman, D. (2005). Hospitality and reciprocity: Working tourists in Dominica. Annals of Tourism Research, 32(2), 407-418.

Holmes, K., K.A. Smith, L. Lockstone-Binney, \& T. Baum (2010). Developing the dimensions of tourism volunteering. Leisure Sciences, 32(3), 255-269.

Jennings, G. (2001). Tourism research. Milton, Australia: John Wiley \& Sons.

Jones, A. (2005). Assessing international youth service programmes in two low income countries. Voluntary Action: The Journal of 
the Institute for Volunteering Research, 7(2), 87-100.

Junker, B.H. (1960). Fieldwork: An introduction to the social sciences. Chicago: University of Chicago Press.

Kaynak, E., \& E. E. Marandu (2006). Tourism market potential analysis in Botswana: A Delphi study. Journal of Travel Research, 45(2), 227-237.

Kislenko, A. (2004). Culture and customs of Thailand. London: Greenwood Press.

Knollenberg, W., N.G. McGehee, B. Bynum Boley \& D. Clemmons (2014). Motivationbased transformative learning and potential volunteer tourists: Facilitating more sustainable outcomes. Journal of Sustainable Tourism, 22(6), 922-941.

Konovsky, M. A., \& S.D. Pugh (1994). Citizenship behavior and social exchange. The Academy of Management Journal, 37(3), 656-669.

Kontogeorgopoulou, N. (2016). Forays into the backstage: Volunteer tourism and the pursuit of object authenticity. Journal of Tourism and Cultural Change. URL: http://www.pugetsound.edu/files/resources/j ournal-of-tourism-and-cultural-change2016.pdf (Accessed on 30.08.2016)

Lee, C., S.K. Kang, P. Long, \& Y. Reisinger (2010). Residents' perceptions of casino impacts: A comparative study. Tourism Management, 31(2), 189-201.

Lepp, A. (2009). Leisure and obligation: An investigation of volunteer tourists' experience at Kenya's Taita Discovery Center. Journal of Leisure Research, 41(2), 253-260.

Lo, A., \& C. Lee (2011). Motivations and perceived value of volunteer tourists from Hong Kong. Tourism Management, 32(2), 326-334.

Mathieson, A., \& G. Wall (1982). Tourism: Economic, physical and social impacts. New York: Longman.

McGehee, N.G., \& K.L. Andereck (2009). Volunteer tourism and the "voluntoured": The case of Tijuana, Mexico. Journal of Sustainable Tourism, 17(1), 39-51.

McGehee, N.G., \& C. Santos (2005). Social change, discourse and volunteer tourism. Annals of Tourism Research, 32(3), 760779.
McIntosh, A.J., \& A. Zahra (2007). A cultural encounter through volunteer tourism: Towards the ideals of sustainable tourism? Journal of Sustainable Tourism, 15(5), 541556.

Molm, L. D. (1991). Social exchange: Satisfaction in power-dependence relations. American Sociological Review, 56(4), 475493.

Molm, L.D., N. Takahashi, \& G. Peterson (2000). Risk and trust in social exchange: An experimental test of a classical proposition. American Journal of Sociology, 105(5), 1396-1427.

Molm, L. D., G. Peterson, \& N. Takahashi (2003). In the eye of the beholder: Procedural justice in social exchange. American Sociological Review, 68(1), 128152.

Morgan, J. (2010). Volunteer tourism: What are the benefits for international development? The VolunTourist Newsletter, 6(2). URL: http://www.voluntourism.org/news-study

andresearch62.html (Accessed on 12.03.2016).

Mostafanezhad, M. (2013). The geography of compassion in volunteer tourism. Tourism Geographies: An international journal of tourism space, place and environment, 15(2), 318-337.

Mostafanezhad, M. (2014). Volunteer tourism and the popular humanitarian gaze. Geoforum 54, 111-118.

Nestora, A., P.Yeung, \& H. Calderon (2009). Volunteer travel insights 2009. Bradt travel guides, Lasso communications. GeckoGo. URL:

http://www.geckogo.com/volunteer/report20 09 (Accessed on 27.03.2016)

Nunkoo, R., \& D. Gursoy (2012). Residents' support for tourism: An identity perspective. Annals of Tourism Research 39(1), 243268.

Nunkoo, R., \& H. Ramkissoon (2012). Power, trust, social exchange and community support. Annals of Tourism Research 39(2), 997-1023.

O' Donoghue, T.A. (2007). Planning your qualitative research project: An introduction to interpretivist research in education. London: Routledge.

Oberg, P., \& T. Svensson (2010). Does power drive our trust? Relations between labor 
market actors in Sweden. Political Studies, 58(1), 143-166.

Ooi, N., \& J.H. Laing (2010). Backpacker tourism: Sustainable and purposeful? Investigating the overlap between backpacker tourism and volunteer tourism motivations. Journal of Sustainable Tourism, 18(2), 191-206.

Palacios, C.M. (2010). Volunteer tourism, development and education in a postcolonial world: Conceiving global connections beyond aid. Journal of Sustainable Tourism, 18(7), 861-878.

Pearce, P. (1994). Tourist-resident impacts: Examples, explanations and emerging solutions. In Theobald, W. (Ed.) Global tourism: The next decade. Oxford: Butterworth Heinemann, pp. 103-123.

Proyrungroj, R. (2013). Orphan volunteer tourism in Thailand: Volunteer tourists' motivations and on-site experiences. Journal of Hospitality \& Tourism Research. DOI: $10.1177 / 1096348014525639$

Proyrungroj, R. (2015). The attitudes of Thai hosts towards western volunteer tourists. European Journal of Tourism Research, 11, 102-124.

Raymond, E.M., \& C.M. Hall (2008). The development of cross-cultural (mis)understanding through volunteer tourism. Journal of Sustainable Tourism, 16(5), 530-543.

Reisinger, Y. (2012). International tourism: Cultures and behavior. Oxon: Routledge.

Richter, L.M., \& A Norman (2010). AIDS orphan tourism: A threat to young children in residential care. Vulnerable Children and Youth Studies, 5(3), 217-229.

Scheyvens, R. (2002). Tourism for development: Empowering communities. Essex: Prentice Hall.

Sharpley, R. (2008). Tourism, tourists and society. $4^{\text {th }}$ ed. Huntingdon: ELM.

Sharpley, R. (2014). Host perceptions of tourism: A review of the research. Tourism Management 42, 37-49.

Simpson, K. (2004). 'Doing development': The gap year, volunteer-tourists and a popular practice of development. Journal of International Development, 16(5), 681-692.

Simpson, K. (2005). Broad horizons? geographies and pedagogies of gap year
(Unpublished $\mathrm{PhD}$ thesis), University of Newcastle, Newcastle, United Kingdom.

Sin, H.L. (2009). Volunteer tourism - "involve me and I will learn"? Annals of Tourism Research, 36(3), 480-501.

Sin, H.L. (2010). Who are we responsible to? locals' tales of volunteer tourism. Geoforum 41(6), 983-992.

Smith, V. (1977). Hosts and guests: The anthropology of tourism. Philadelphia PA: University of Pennsylvania Press.

Stein, S. M., \& T.L. Harper (2003). Power, trust, and planning. Journal of Planning Education and Research, 23(2), 125-139.

Stoddart, H., \& C.M. Rogerson (2004). Volunteer tourism: The case of habitat for humanity South Africa. GeoJournal, 60(3), 311-318.

Sutton, Jr W. (1967). Travel and understanding: Notes on the social structure of touring. Journal of Comparative Sociology, 8, 217-223.

Teye, V., S.F. Sönmez, \& E. Sirakaya (2002). Residents' attitudes toward tourism development. Annals of Tourism Research, 29(3), 668-688.

Tomazos, K., \& R. Butler (2009). Volunteer tourism: The new ecotourism? Anatolia: An International Journal of Tourism and Hospitality Research, 20(1), 196-211.

Tourism Authority of Thailand (TAT) (2010). TAT Fine-tunes its 2011marketing strategies in Europe. URL: http://www.tatnews.org/tat_release/ detail.asp?id=5169(Accessed

on 31.08.2016).

Tourism Research and Marketing (TRAM) (2008). Volunteer tourism: A global analysis. Arnhem, Netherlands: ATLAS.

United Nations Environment Programme (2005). Tsunami Thailand Layout. URL: http://www.unep.org/tsunami/reports/TSUN AMI_THAILAND_LAYOUT.pdf (Accessed on 31.08. 2016).

United Nations Thailand (2008). Earthquake/Tsunami Victims Relief Efforts, Department of Disaster Prevention and Mitigation, Ministry of Interior, Thailand. URL: $\quad$ http://www.un.or.th/pdf/ddpm tsunami.pdf (Accessed on 31.08. 2016).

Uriely, N., \& A. Reichel (2000). Working tourists and their attitudes to hosts. Annals of Tourism Research, 27(2), 267-283. 
Van den Berghe, P. L., \& C.F. Keyes (1984). Introduction tourism and re-created ethnicity. Annals of Tourism Research, 11(3), 343-352.

Van der Meer, K. (2007). Perspectives on ecotourism and volunteer tourism in post tsunami Khao Lak, Thailand (Unpublished Master's degree dissertation). University of Victoria, Canada.

Vasquez, E. (2010). Do celebs like Jolie inspire voluntourism?

URL: http://edition.cnn.com/2010/TRAVEL/08/10/ celebrity.humanitarian.travel/ (Accessed on 01.09.2016)

Ward, C., \& T. Berno (2011). Beyond social exchange theory: Attitudes toward tourists. Annals of Tourism Research, 38(4), 15561569.
Wearing, S. (2001). Volunteer tourism: Experiences that make difference. Wallingford: CABI.

Wearing, S., \& N.G. McGehee (2013). Volunteer tourism: A review. Tourism Management, 38, 120-130.

Zafirovski, M. (2005). Social exchange theory under scrutiny: A positive critique of its economic-behaviorist formulations. Electronic Journal of Sociology, 2, 1-40.

Zahra, A., \& A.J. Mclntosh (2007). Volunteer tourism: Evidence of cathartic tourist experiences. Tourism Recreation Research, 32(1), 115-119.

Zhang, J., H. Xu, \& W. Xing (2016). The hostguest interactions in ethnic tourism, Lijiang, China. Current Issues in Tourism. DOI: 10.1080/13683500.2016.1178218 